\title{
The Experiential-Learning Track: Career Exploration, Student Interest, \& Applied Classroom-Learning in Small Rural Junior-Senior High Schools
}

Michael Turnlund

Clark Fork Jr/Sr High School (retired), mturnlund@gmail.com

Follow this and additional works at: https://pdxscholar.library.pdx.edu/nwjte

Part of the Secondary Education Commons

Let us know how access to this document benefits you.

\section{Recommended Citation}

Turnlund, Michael (2019) "The Experiential-Learning Track: Career Exploration, Student Interest, \& Applied Classroom-Learning in Small Rural Junior-Senior High Schools," Northwest Journal of Teacher Education: Vol. 14 : Iss. 2 , Article 5.

DOI: https://doi.org/10.15760/nwjte.2019.14.2.5

This open access Article is distributed under the terms of the Creative Commons Attribution-NonCommercialShareAlike 4.0 International License (CC BY-NC-SA 4.0). All documents in PDXScholar should meet accessibility standards. If we can make this document more accessible to you, contact our team. 


\section{The Experiential-Learning Track: Career Exploration, Student Interest, \& Applied \\ Michael Turnlund Clark Fork Junior/Senior High School \\ Classroom-Learning in Small Rural Junior-Senior \\ High Schools}

Budgetary constraints can limit academic programs and elective offerings in small rural high schools. It is difficult to staff schools with teachers who hold the required credentials to offer elective courses that match student interests and future career or post-secondary education goals. This article details a strategy used by one small school in Idaho to address the problem. The ExperientialLearning Track Program allows for "hands-on" opportunities tied to learning objectives, and targets career and post-secondary education goals of individual students. Outcomes of the project included an increase in student population numbers and more connections with the local community. Keywords: Experiential learning, career preparation, student interest

\section{Introduction}

Budgetary constraints can limit academic programs and elective course offerings at high schools of any size and student population. The smallest secondary schools struggle to offer enough courses that allow students to meet state-mandated graduation requirements within the credential constraints of their teaching staff. At times there are simply too few teachers with the requisite credentials to allow for an expansive selection of elective courses. While schools can provide the state-required courses, they may not be able to offer many elective courses. More specifically, budgetary and staffing constraints reduce a school's ability to offer elective courses matched to student interest and aligned with their future career or post-secondary education goals. As such, this format of shortage is not a suitable or preferred — or equitable — option for many students. 
Increasingly, the narrowing specificity of teaching credentials for secondary education instructors exacerbates this problem. The Experiential-Learning Track Program (ELT) was developed as a mechanism to overcome educational limitations through "hands-on" learning opportunities designed around student interests. The program allows for experiential-learning opportunities tied to specific classroom learning objectives, and targets individual students' stated career and post-secondary education goals. The ELT Program utilizes weekly, biweekly, and/or monthly "tracks" that are held in lieu of the standard school day.

\section{Background}

Clark Fork Jr/Sr High School (CFHS) sits in the small and relatively remote community of Clark Fork, Idaho, (pop. 536) in the Idaho panhandle region. The community is situated ninety miles east of Spokane, Washington, and near the Idaho-Montana border. The school is part of the Lake Pend Oreille School District, about 25 miles outside of Sandpoint, Idaho. The school's attendance zone is one of the largest in the state of Idaho and includes the twin communities of Hope and East Hope, with a combined population of 296, eight miles to the west. The school is classified as "rural and remote" by the state of Idaho. Prior to initiating the current free lunch program, approximately $80 \%$ of students qualified for free or reduced-price school lunches. The student body is predominantly white and drawn from working-class families.

The instructional and administrative staff at CFHS faced what appeared to be an insurmountable problem: how to offer students coursework that aligned with both student interest and student post-secondary career goals within the constraints of a minimized academic schedule. In other words, how to offer meaningful and relevant courses to students with a minimum number of available staff.

Due to chronic student enrollment losses, the student population at the combined junior-senior high school had declined from 130 students to 84 students by the end of the 2013-2014 academic year. The decline was generated in part by an economic downturn which forced families to leave the CFHS attendance area for job prospects elsewhere and in part due to secondary-education competition (ie: lenient homeschool regulations, an online high school option, attractive academic opportunities at the larger Sandpoint High School). Consequently, the decline in enrollment caused teaching staff reductions from 12.5 full-time equivalent (FTE) teachers to 8.5 FTE, the minimum number that could provide a four-year course schedule that met the minimum graduation requirements of the state of Idaho. But nothing more.

In addition, elective courses at CFHS were not specifically tailored to student interest; rather, elective courses were aligned with staff teaching credentials. Elective course choices were sparse in the humanities and heavy in 
the social sciences (e.g., psychology, sociology, anthropology, etc.) There were no vocational or technical education courses available. Upper-level math courses were offered, with limited interest from the student body. Similarly, the two elective courses that offered college credit (100-level US History and 100-level English) were also of limited interest to students. Online courses were available, but students had limited success to or interest in an online format.

From a series of staff workshops, multiple targets were identified that required redress: student motivation career readiness (especially in fields that do not require a traditional four-year college education), post-secondary education readiness, expanding course selection to more broadly match student interests, and to provide more 'hands-on' learning opportunities. An additional goal was to increase the student population at CFHS by drawing in local students attending school online or at home, some of whom participated in the afterschool sport programs, but did not attend classes.

The state of Idaho allows schools to operate within a four-day schoolweek format as long as they meet the minimum number of required school days, contact minutes, and provide the minimum number of credits required for a diploma. The staff at CFHS recommended to superimpose a four-day school week curriculum and schedule over a five-day school week. The Lake Pend Oreille School District, the larger school district in which CFHS is nested, required CFHS to maintain the five-day school week. That fifth day, a Friday, could then be used to create a program to meet the objectives described above. The next question was: what would that fifth day look like?

\section{The Experiential-Learning Track Program}

The program developed for this dedicated fifth day is called the Experiential-Learning Track (ELT) Program, or simply the track program. Instead of reviewing the history of the program across the four years of development, it is more pertinent to examine the program as it exists today. Originally the program encompassed over 30 "track" days spread across the school year. That number has been reduced and maintained at the current 22 academic days, 11 in each semester.

Ambitiously, the program was designed to meet all the goals that had been identified during the teacher workshops. Entire school days are set aside to provide experiential learning opportunities for students in areas that interest them, and in contexts which are not otherwise available at the school site. These learning opportunities are concentrated into themed "tracks." The content of each track is determined through consensus gathered from student surveys. As the student performance within the tracks is not graded (the Independent Track excepted, see below), teachers are not required to be credentialed in the nominal 
"content area" of the track. For example, a teacher could lead a science-related track without holding science education credentials.

Experiential-learning is defined by the staff at CFHS as day-long, out-ofthe-classroom, "hands-on" learning opportunities where students complete projects, tasks, or are otherwise engaged in self-directed learning. Additionally, there are experiential-learning activities that students choose according to individual interest, curiosity, or to either explore or prepare themselves for their post-high school careers.

Examples from the ELT program that demonstrate experiential learning include exploring automobile engineering and/or a career in automobile repair by building a motor-powered buggy; learning about therapies for, and careers related to, helping developmentally-delayed children by working directly with such children under the guidance of professional therapists; learning about how premodern cultures survived in the wild by spending the day gathering natural foods and preparing them over a fire without using any modern implements.

Teachers serve as track leaders and develop the curriculum for each track and often work with an assistant. Leaders are paid a stipend, assisting teachers are not. The stipend is meant to compensate track leaders for the time they use to plan and coordinate the individual tracks that they lead. Track leaders typically use the summer break to construct a year-long curriculum, to make community contacts, gather materials, arrange trips and reserve buses, etc., as well as provide the ongoing leadership the track requires during the school year.

Twelfth-grade and advanced eleventh-grade students participate in the Independent Track. The rest of the students select the track in which they want to participate on a first-come basis, with the oldest students choosing first: eleventhgrade students select first, followed by tenth-graders, and then the ninth-grade students. Junior high students (grades seven and eight) participate in a separate track program that is more structured and age appropriate.

The ELT program has been successful and all the original objectives have been met. These objectives, in part, included:

- Improving student engagement at school; students and parents have embraced the program;

- Requiring twelfth-grade students to participate in a semester long jobshadowing project with a mentor of their choice, culminating in a public, juried presentation of their experience as a graduation requirement;

- Updating track options with half-yearly student surveys to align with student interests.

\section{Expansion \& Additional Benefits}

The ELT program has expanded to other schools in the Idaho panhandle region. Schools currently using the ELT program model include Mullan Jr/Sr 
High School, in Mullan, and Lakeside Jr/Sr High School in Plummer. Two additional small rural schools in a neighboring state have also expressed interest in implementing the program.

Clark Fork instructional staff members also learned to use the ELT program as a way to apply what is learned in the classroom into the field. Teachers intentionally construct many of the ELT program activities to provide specific learning opportunities connected with the needs of people employed in the field. The teaching staff utilizes the ELT program to provide learning opportunities that would otherwise be unlikely or less frequent due to the constraints of a minimalist academic course offerings or the limits of a 50-minute class period. For example, many students will still not have the option to fit an art class elective into their four-year academic plan. Subsequently the availability of the Arts \& Culture Track provides an opportunity for experiencing art. Similarly, the Arts \& Culture Track was able to connect a study on Latin American culture with Spanish language students. A track day was used to explore the art of the Mexican Day of the Dead holiday, followed by a Broadway show in Spokane, Washington, on the same theme. As one teacher observed, the track programs "create relevance and excitement" to classroom learning.

The ELT program can also fill gaps in student learning. For example, while there is no longer an elective course available on Idaho history, students who participated in the Outdoor Track were able to learn more about Idaho history and engage in a public service project. At nearby Farragut State Park, students cleared hiking paths and painted structures for the upcoming tourist season. In addition, they participated in a guided tour walking lecture of the facilities hosted by a park ranger and learned the role that Farragut played in Idaho history as the largest U.S. naval training base during World War II.

The student population of CFHS increased due to the ELT program, but not as anticipated. While the student population increased by 53 percent across five years (from 84 to 129 students, respectively), the majority of the increase did not come from recruiting local homeschooled or online-schooled students. Instead, most of the new students came from Sandpoint, the primary population center in the county and 25 miles to the west. Sandpoint is home to the district office and two high schools. Students are allowed to attend any school within the school district; subsequently high school students in Sandpoint have been transferring to CFHS, requiring a dedicated school bus to transport students from Sandpoint to CFHS each school day. These new students compose $18 \%$ of the current CFHS student body.

\section{Track Specifics \& Examples}

The majority of ELT program tracks are designed as group activities in which all students in the track participate, with the exception of the Tech Track 
and the Independent Track. Some current and former tracks include: the Outdoor Track, centered on outdoor activities and careers; the Arts \& Culture Track, centered on activities and careers in the humanities; the Animal Science Track, centered on activities and careers such as veterinary medicine; the Tech Track, centered on career and technical activities and careers; the Business Track, centered on activities and careers in entrepreneurship; and the Independent Track, which is a career exploration and mentorship program.

Outdoor Track: River Delta Restoration Project. Under the guidance of wildlife biologists with the Idaho Department of Fish and Game, students participated in a series of workshops and on-site outings to help restore a local river delta. Student participation in the Clark Fork River Delta Restoration project involved planting native trees and shrubs and working directly with wildlife biologists and field technicians. Students learned about career opportunities in wildlife and environmental conservation and about river and lake biomes, how partnerships between private industry (power companies) and government agencies operate, and the "nuts and bolts" of how an ecosystem is restored.

Additionally, this project gave students the opportunity to exercise their role as citizens by participating in an extensive community and environmental improvement project that encompassed multiple track days and provided further learning opportunities beyond the restoration project.

Parks \& Recreation Track: Fly-Fishing. In this track, students learned about fly fishing and, specifically, how to tie artificial flies. A professional fly-fishing instructor from a local outdoor supply store led the class. In addition to learning how to tie flies, the students were led through a study of the life stages of aquatic insects, as the artificial flies are created to mimic specific stages of an insect's life. Students also learned about the physiology of rivers and streams, as well the relation between rivers, streams, and watersheds.

An important follow-up activity was fly fishing using the student-tied flies with members of Trout Unlimited, a local conservation organization. For many students, this was a first opportunity to try sportfishing. Additionally, students learned to distinguish between the different species of game fish and their specific biological niches. While the fly tying and fly fishing were the experiential components, students learned about careers in the retail trades and in professional recreation services.

Tech Track: Long-term projects. The Tech Track is unique in format in that students, whether individually or in small groups, engage in a project that might extend over many weeks or months. The focus of the Tech Track includes all 
aspects of automobile repair (ie: electrical systems, engines, fuel systems, transmissions, body repair); fabrication (ie: welding, CNC machining, 3D printing); computer systems and repair; robotics (including aerial and aquatic drones); and woodworking. The experiential-learning opportunities are diverse as the Tech Track teacher is a former engineer with extensive field experiences.

In the Tech Track, students plan and develop extensive, relatively longterm projects. A single project, such as rebuilding an engine, might extend over an entire semester, providing the student or team of students the time necessary to master and complete the objective. A project can encompass the entire academic year or more, if necessary.

Independent Track. The Independent Track was originally designed to offer students the opportunity to work in a career setting and experience a variety of career fields. It has since become integrated into the school's graduation requirements. Twelfth-grade CFHS students are now required to participate in the Independent Track in order to fulfill a senior project state-mandated graduation requirement. The Independent Track is available to any students at the tenth- and eleventh-grade levels, although the senior-project must be completed during grade 11 or 12 . Students may participate in the Individual Track multiple times, whether short-term (one semester) or long-term (multiple semesters). Participation is driven by personal interests.

Students enrolled in English IV (12 ${ }^{\text {th }}$-grade English) are required to participate in the Independent Track during the first semester of the school year. Students construct a senior-project which entails a juried public presentation given before an audience consisting of parents, community members, business professionals, and eleventh-grade students.

Participation in the Independent Track by tenth- and eleventh-grade students is encouraged, as it has been found that mentored work experiences in the Independent Track have had the most significant impact on students' future post-secondary decisions, both career and college paths. The success of Independent Track reflects two important aspects of student choice offered by the ELT program. First, students often use their prior experiential-learning track experiences to determine their Independent Track choice; a greater variety of prior experiences help to guide the student toward an appropriate Independent Track selection. For example, if a student really enjoyed learning the skills of automobile repair in the Tech Track, the student might seek out a similar opportunity in the Independent Track. Second, students frequently discover that what they had sought out originally as a potential career-choice in the Independent Track ended up not being what they had anticipated or even enjoyed. For example, one student was intent on becoming an elementary education teacher. Subsequently, she participated in a semester-long mentorship in a third- 
grade classroom. The experience was successful in that the student realized that she did not, after all, want to become an elementary-education teacher, an important discovery. In another example, one student was able to identify a future career path. The student was interested in becoming an ultrasound technician. After being placed with a mentor in the radiology department at the county hospital, she realized she was no longer interested in pursuing that field. Next, she thought that working in real estate might be interesting. After spending the next semester working with a local real estate agent, she discovered that this, too, was not a good fit for her. Finally, she spent a semester working with a licensed cosmetologist, which proved to be a compelling choice for her and she is now pursuing cosmetology and hair design.

The Independent Track has also been successful as a form of community outreach. Business owners and community leaders have been enthusiastic supporters, with many initiating contact to serve as potential mentors. Students have participated in such career fields as heavy equipment construction and repair, real estate sales and service, aerospace engineering, city administration, nursing, various technical medical fields, computer repair and support, electrical engineering, hospitality, therapeutic equestrian training, and psychological counseling.

Junior-High Track Program. Junior high students (grades seven and eight), participate in a modified track program. The ELT program for junior high students is a modified version of the high school program. Instead of selecting a specific track for a semester or more, junior high students participate together in a series of "mini-tracks" - each of limited duration - over the course of the year. For example, junior high students might spend three or four consecutive track days learning about painting from a professional artist. This might be followed by a similar number of consecutive track days in the forest, learning about survival, search and rescue, forestry, or woodlands management. Over the course of the academic year, junior-high students participate in six or more different track experiences.

\section{Funding}

The original two years of the ELT program at CFHS were funded by grants from the Panhandle Alliance for Education, a local private educationsupport nonprofit. Subsequently, funding for the ELT program at CFHS has been provided by a line-item addition to the school district budget. Additional monies for special projects, equipment, or travel are solicited from local, regional, and state-wide organizations or businesses interested in supporting the ELT program. As the ELT program is a normal part of the education system at CFHS, there are 
no additional funding or participation requirements for students. All students participate equally.

\section{Conclusion}

Due to limits imposed by minimum staffing levels and financial constraints, small rural schools struggle to meet diverse student interests and career goals in tangible ways. The Experiential-Learning Track Program provides an effective and adaptable methodology to meet these student needs and interests. The program not only engages students and staff members in a meaningful way, but also parents, community leaders, and other stakeholders. It has proven effective in meeting its objectives.

Author's Note: The information in this paper is drawn from a summary, itself a compilation of interviews and surveys conducted by the author to learn more about the respective ELT programs at the schools described. If you would like to obtain a no-cost electronic copy of the summary, contact the author at mturnlund@gmail.com. 